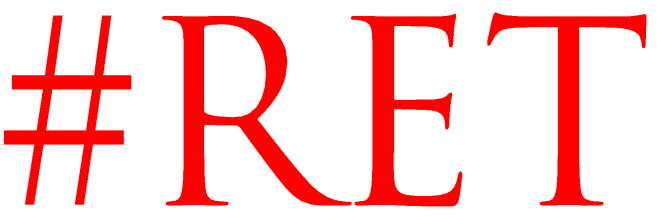

Revista Española de la Transparencia

Núm. 12. Primer Semestre. Enero-Junio de 2021, pp. 125-144

ISSN 2444-2607. www.revistatransparencia.com

DOI: https://doi.org/10.51915/ret.122

ESTUDIOS Y ARTICULOS

\title{
Los riesgos de corrupción de los lobbies
}

\author{
Iolanda M. Aguilar Juncosa ${ }^{1}$ \\ Universitat Autònoma de Barcelona \\ España
}

ORCID: 0000-0002-1137-3430

RECIBIDO: 3 de octubre de 2020 ACEPTADO: 9 de marzo de 2021

RESUMEN: Los lobbies o grupos de interés son inherentes a las sociedades democráticas contemporáneas y son un elemento de garantía de representatividad, así como un mecanismo facilitador de conocimiento técnico a los gobernantes y decisores públicos.

Para evitar los riesgos de corrupción por una influencia indebida y que su actividad sea beneficiosa para la sociedad, hay que establecer medidas preventivas como la transparencia de su actuación a través del registro obligatorio de los grupos de interés y la publicación de la agenda de los altos cargos, la elaboración de sistemas de integridad institucional y la igualdad de acceso de todos los intereses, no solo en el ámbito regulatorio, sino especialmente en el ámbito de la contratación pública.

PALABRAS CLAVE: lobbies, grupos de interés, influencias, corrupción.

CONTENIDOS: 1. La legitimidad de la actividad de influencia. - 2. Los riesgos de corrupción. - 2.1. Las puertas giratorias. - 2.2. La captura reguladora y técnica. - 3. Las medidas de prevención. - 3.1 La transparencia. - 3.2. La integridad. - 3.3. La igualdad de acceso. - 4. Conclusiones. - Bibliografia.

\footnotetext{
${ }^{1}$ Doctoranda en Derecho en la Universitat Autónoma de Barcelona. Licenciada en Ciencias Políticas y Administración por la misma universidad. Licenciada en Derecho por la Universitat Oberta de Catalunya. Máster en Administración y Gobierno Electrónico por la misma universidad. Máster en Dirección Pública por ESADE. Profesora Colaboradora en la Universidad Oberta de Catalunya en el Departamento de Derecho y Ciencias Políticas y Directora de Servicios del Departamento de Justícia de la Generalitat de Catalunya. Su línea de investigación se centra en la corrupción pública y la relación entre los lobbies y el delito de tráfico de influencias.
} 
El presente artículo está basado en la ponencia que se presentó con el título Los riesgos de corrupción de la actividad de influencia que fue seleccionada para su presentación en el $V$ Congreso Internacional de Transparencia, celebrado en Madrid entre el 28 de septiembre y el 1 de octubre de 2020.

\section{The risk of lobbies corruption}

ABSTRACT: Lobbies or interest groups are inherent in contemporary democratic societies and are an element of guarantee of representativeness, as well as a mechanism facilitating technical knowledge to public rulers and policy makers. In order to avoid the risks of corruption from undue influence and its activity being beneficial to society, preventive measures such as the transparency of its action must be established through the compulsory registration of interest groups and the publication of the agenda of senior officials, the development of institutional integrity systems and equal access to all interests, not only in the regulatory field, but especially in the field of public procurement.

KEYWORDS: lobbies, interest groups, influences, corruption. 


\section{La legitimidad de la actividad de influencia}

En los sistemas democráticos contemporáneos hablar de democracia equivale a hablar de representatividad, y la base de dicha representatividad es que permite definir el interés general en un contexto de intereses plurales. En este sentido, la principal función de los poderes públicos será tomar las decisiones más equitativas posibles para todos y cada uno de los intereses privados, sin perjudicar el interés común y sin el lobbismo y la actividad de los grupos de interés, esto no sería posible (Xifra, 2009:10). Si adoptamos una visión pluralista de la sociedad, otorgaremos un papel relevante a la acción de los grupos de interés, entendida como un complemento de la representatividad electoral, y donde debería haber un alto grado de participación política. El ideal del pluralismo es que todos los intereses partan de posiciones de igualdad y todos tengan garantizada la capacidad de influencia (García, 2016:69).

Pero esta visión ideal ignora el hecho de que la realidad muestra grandes diferencias en la capacidad de influencia entre los diversos intereses. Para Bobbio (1997:519) en toda sociedad hay una minoría que es siempre la única que detenta el poder, en sus diversas formas, frente una mayoria que carece de él. En los sistemas neocorporatistas, en contraposición a los pluralistas, los grupos de interés más representativos gozan de privilegios en el acceso a las instituciones, tanto a través de contactos con los funcionarios y cargos públicos, o participando en la toma de decisiones, convirtiendo a algunos grupos en codecisores de las políticas, obteniendo casi un monopolio de la representatividad. En este sentido, según Michels (2001:83) y citando a Proudhon, los sistemas representativos no garantizan la igualdad entre los diversos intereses, ya que los representantes de la soberanía popular en cuanto asumen el poder comienzan a trabajar para consolidar y reforzar su influencia. En consecuencia, la minoría que gobierna, no sólo es la del gobierno legalmente constituido, sino el resultado de la confluencia e influencia de los intereses de los grupos dominantes.

Sin embargo, presionar o influenciar a los decisores públicos no debería tener connotaciones negativas. En democracia es perfectamente legítimo que la sociedad civil presione a los gobernantes para defender sus intereses, ya sea un sector de actividad, una región, una clase profesional o una empresa. Martins (2006:9) utiliza el símil de una manifestación de trabajadores en defensa de sus condiciones laborales, y afirma que en el fondo están haciendo de lobby sin saberlo. En este sentido se hace evidente que en países totalitarios es más difícil, por no decir imposible, que la sociedad civil se organice para presionar a un gobierno dictatorial en defensa de los intereses. Podriamos decir que el lobby es un elemento más de un sistema democrático. 
Pero la legitimidad de los grupos de interés no debe verse únicamente desde la óptica de la representatividad, sino también desde su funcionalidad. Tanto los gobernantes como el poder legislativo, necesitan datos técnicos para poder desarrollar eficientemente sus competencias. Así, uno de los principales fundamentos del lobby es completar las lagunas de conocimiento que tiene el poder ejecutivo o legislativo, respecto al objeto sobre el que debe tomar una decisión o legislar. Por tanto, el contacto con los grupos de interés permite a los decisores públicos, adoptar decisiones de mayor calidad y al mismo tiempo ser más eficaces. En este sentido, se podría considerar el lobbismo como una herramienta de transmisión del conocimiento al poder público (Xifra, 2009:13).

\section{Los riesgos de corrupción}

A pesar de que como hemos visto la actividad de los lobbies es inherente a los sistemas democráticos, se hace necesario que su acción no dificulte o impida la imparcialidad entendida como una de las claves de la calidad gubernamental. Ello debe comportar que la actuación de los poderes públicos no se vea alterada por relaciones privilegiadas o las preferencias personales y únicamente se guie por criterios generales no individualizados. El hecho que la actividad de los grupos de interés se realice con frecuencia fuera de los mecanismos formales de actuación administrativa con el objetivo de influenciar e incidir en la agenda política o en la toma de decisiones y que los canales de comunicación y actuación sean informales, genera el riesgo a una actuación administrativa ilegal.

Según Revuelta y Villoria (2016:409) la relación entre los grupos de interés y la corrupción tiene que entenderse desde una concepción de la corrupción que no sea meramente jurídica, sino desde una visión politológica y normativa. Es curioso el término utilizado por estos autores de "corrupción legal", que, aunque parece un oximoron, la definen como "prácticas que atentan contra los principios básicos que delinean los limites entre el político y la economía, prácticas que pueden ser legales pero que son utilizadas para crear politicas o leyes que favorecen intereses económicos privados y dañan el interés general". Ello nos lleva a diferenciar entre la corrupción jurídica que está penalizada por las normas ${ }^{2}$, la corrupción ética que correspondería a las conductas reprobables según las concepciones ético-sociales dominantes en un momento histórico y en una cultura concreta, y finalmente la corrupción política o pública, a caballo entre las otras dos, y que contempla una perspectiva más amplia del concepto de corrupción.

\footnotetext{
${ }^{2}$ En el Código Penal español no existe un delito de corrupción propiamente dicho, ni tan solo una sistematización de los delitos relacionados con la corrupción política bajo un mismo título identificativo del bien jurídico protegido, que debería ir más allá de la simple objetividad e imparcialidad en el ejercicio de la función pública, como ocurre en los delitos contra la Administración pública regulados en el título XIX del CP.
} 
En esta línea Malem (2001:581) considera que son actos políticos corruptos aquellos que reúnen las siguientes características: un acto de corrupción implica la violación de un deber posicional; para que exista un acto de corrupción política debe haber un sistema normativo de carácter político que le sirva de referencia; un acto de corrupción política no siempre conlleva una acción antijurídica; y los actos de corrupción política siempre están vinculados a la expectativa de obtener un beneficio extraposicional. Cabe decir que muchas agencias anticorrupción, utilizan esta visión amplia de la corrupción, superando el marco legal establecido 3 .

Y volviendo a la actividad de influencia que realizan los lobbies, la percepción popular asocia frecuentemente el término lobby a prácticas reprobables cercanas a la corrupción. Pero dicha percepción no es igual en todas las culturas. En el caso estadounidense, cuna del lobbismo, éste se entiende como un instrumento de participación de la sociedad civil en la vida pública y por tanto tiene bastante más aceptación que en Europa, que lo entiende como una práctica más cercana al tráfico de influencias (Xifra, 1998:33).

En España y otras culturas latinoamericanas, no ha arraigado la cultura de los lobbies porque ha existido una práctica de favores que ha acabado funcionando en dos sentidos, el que pide un favor se convierte en "deudor" de un favor similar a otra persona, y el "acreedor "se considerará en pleno derecho, más tarde pedir de un favor que pueda conseguir otro y se cierra el ciclo. Esta práctica ha sido socialmente aceptada durante muchos años, sin embargo, a medida que los diferentes sistemas democráticos han ido consolidando y volviéndose más maduros, los abusos e injusticias han hecho cuestionar la ética de esta práctica y de ahí la necesidad de regulación (Martins, 2006:10).

Des de la perspectiva de la corrupción jurídica, la tipificación del delito de tráfico de influencias, introducido en el Código Penal en 1991, había de servir para marcar el límite entre la actividad legal y legitima de los lobbies y la ilegal. La preocupación del legislador en aquellos momentos era el abuso de la proximidad al poder para el enriquecimiento personal, y especialmente el ejercicio de la influencia sobre la Administración para que actuara en favor del interés privado (Cugat,1997:25). Así el tipo nuclear del delito consiste en utilizar ilegítimamente influencias, previa prevalencia del cargo o de relaciones personales, para conseguir una resolución beneficiosa económicamente.

\footnotetext{
${ }^{3}$ Para la Oficina Antifrau de Catalunya (primera en crearse en todo el Estado) todo acto de corrupción supone el incumplimiento consciente de la obligación de un decisor público (aunque también aplicable al ámbito privado) quien, en abierta deslealtad con el mandato asumido legalmente 0 contractualmente, únicamente persigue la obtención de un beneficio particular, al margen de la ciudadanía o de los legítimos intereses de terceros. El acto corrupto siempre se produce en un marco normativo concreto que le sirve de referencia, ya sea de tipo legal -donde hablariamos de corrupción legal- o contractual, como podria ser la vulneración de normas de responsabilidad social corporativa o inherentes al riesgo reputacional, que estaría relacionado con la corrupción ética.
} 
La poca jurisprudencia existente de dicho tipo penal, ha configurado los dos elementos constitutivos del delito: el ejercicio de influencia y que esta se ejerza con prevalencia del cargo o por las relaciones personales. La prevalencia exigida es la que diferencia la simple influencia de la influencia constitutiva de delito 4 .

No obstante, la regulación del tipo delictivo de tráfico de influencias no se ha mostrado eficiente para combatir las influencias delictivas debido a las dificultades probatorias y de aqui que exista un debate doctrinal al respecto entre autores que abogan por prescindir de dicho delito (Cugat, 2014:21), y los que consideran que hay que endurecer las penas por su comisión (Muñoz, 2013:76). Personalmente creo que ha de existir una figura delictiva que penalice las influencias que sobrepasan la actividad legítima de los grupos de interés por los riesgos de corrupción que existen. La voluntad del legislador era dar entidad propia a la influencia y no como mera inducción delictiva a otros delitos, pero creo que se deberían penalizar con el tipo de tráfico de influencias las grandes redes de corrupción, porqué afectan a la dimensión de la integridad institucional y a la propia cultura organizativa. En el caso de las redes de corrupción, los traficantes de influencias utilizan su ventaja posicional para crear un sistema de interrelaciones que les permite obtener de manera segura un beneficio "cuando llega el momento". Si atacamos mediante el delito de tráfico de influencias a las grandes redes de intereses, podemos evitar actos futuros de cadenas de favores.

\footnotetext{
4 De acuerdo con la STS 373/2017, de 24 de mayo, no sería suficiente la mera sugerencia o recomendación aséptica y esporádica, sino que es necesario por un lado que la conducta se realice por quien se encuentra en una situación de ascendencia, y que la influencia tenga entidad suficiente para ser potencialmente eficiente para la situación prevalente que ocupa quien influye. Por lo tanto, este ascendente e influencia debe quedar acreditado en la relación de hechos probados.

Esta influencia, según la STS 335/2006, de 24 de marzo, debería consistir en una presión moral eficiente sobre la acción o la decisión de otra persona, derivada de la posición o status del sujeto activo. Esta presión moral se debe realizar sobre la voluntad del que tiene que resolver y debe alterar el proceso motivador del decisor, introduciendo a su motivación elementos ajenos a los intereses públicos que deberian ser los únicos ingredientes de su análisis, previo a la decisión, por lo que su resolución o actuación sea debida a la presión ejercida. En este sentido no es necesario que la influencia termine con éxito es suficiente su capacidad a tal efecto.
}

En cuanto a la prevalencia, según la STS 2056/2018, de 8 de junio el Código Penal contempla tres modalidades de prevalencia:

- Por el ejercicio abusivo de las facultades de un cargo.

- Por una situación derivada de una relación personal (amistad, familiar ...).

- Por una situación derivada de relación jerárquica utilizada de forma desviada, ejerciendo una presión moral sobre el funcionario influido.

Es por ello, que de acuerdo con la STS 485/2016, de 7 de junio, también quedaría excluido del ámbito del tipo delictivo del art. 428 CP la actuación de los funcionarios que se dirigen a quien debe resolver, aun siendo superiores si no existe un abuso de la jerarquía. Por el contrario, en el caso del art. 429 CP tampoco sería suficiente que un ciudadano trate de influir a un funcionario si no mantiene con él una relación que pueda considerarse personal y de prevalencia. 
Por otro lado, merecen otro tratamiento las influencias individuales entre personas físicas, menos graves por no afectar de forma suprafuncional a la institución pública donde se producen, y en este caso coincido con Martínez (2005:50), que no se deberían perseguir como tráfico de influencias sino como delito concreto cometido por el funcionario destinatario de la influencia ya sea prevaricación, cohecho o fraude, sin que sea necesario adelantar la barrera de protección penal hasta estos límites, en virtud del principio de intervención mínima.

Desde la perspectiva de la corrupción pública, sí que observamos conductas que, aunque en algunos casos no constituyan un delito de corrupción si que son reprobables éticamente y pueden llegar a vulnerar normas administrativas. Algunos ejemplos de malas prácticas o riesgos de corrupción relacionados con la actividad de los grupos de presión son las puertas giratorias y la captura reguladora y técnica.

\subsection{Las puertas giratorias}

El fenómeno conocido con la expresión puertas giratorias (revolving doors o pantouflage), consistente en el movimiento de profesionales que pasan a trabajar del sector público al privado o a la inversa, puede comprometer la integridad y la imparcialidad de los servidores púbicos. Según la Oficina Antifrau de Catalunya ${ }^{5}$, el riesgo de corrupción existe por el hecho de que los servidores públicos que pasan al sector privado puedan utilizar indebidamente la experiencia, la información privilegiada y los contactos obtenidos en el ejercicio del cargo público para beneficiar al privado por el que trabaje o bien a sus clientes corporativos haciendo de lobista.

No obstante, si queremos atraer el talento y los mejores profesionales al sector público, se hace necesario adoptar medidas ponderadas, entre la atracción de dicho talento y el establecimiento de mecanismos que eviten dichos riesgos de corrupción, porque de lo contrario los únicos candidatos de que dispondrá la Administración serán los políticos, cuya única experiencia profesional sea la militancia en un partido.

Ha quedado demostrado que los actuales instrumentos de prevención como son las declaraciones de bienes y de actividades en la fase de selección, y el período de enfriamiento de dos años tras el cese ${ }^{6}$, en que los altos cargos no pueden prestar servicios en entidades privadas que hayan resultado afectadas por decisiones en las que hayan participado no son suficientes, ni eficaces. $Y$ ello, porque los datos nos demuestran que la Oficina de Conflicto de Intereses de la

\footnotetext{
${ }^{5}$ Véanse las herramientas de detección de los conflictos de interés en: www.antifrau.cat/

${ }^{6}$ Art. 15 de la Ley 3/2015, de 30 de marzo, reguladora del ejercicio del alto cargo de la Administración General del Estado.
} 
Administración General del Estado autoriza la práctica totalidad de las peticiones realizadas por los cargos públicos que quieren iniciar una actividad profesional durante el período de enfriamiento ${ }^{7}$. Y ello no sería preocupante si las autorizaciones se realizaran en los supuestos en que queda meridianamente claro que no existe conflicto de intereses, el problema es que son numerosos los casos en que ello no es asi ${ }^{8}$.

Pero si nos interesa atraer el talento al sector público, tampoco podemos pretender que si la Administración "ficha" a un profesional con gran experiencia en un sector concreto, las condiciones sean en primer lugar, que cobrará seguramente menos que un alto directivo del sector privado, y segundo, que después de su cese deberá estar durante dos años sin poder retornar a su oficio en dicho sector, porque seguramente al tratarse del mismo ámbito profesional donde ha prestado servicios en el sector público y de donde procedía en el privado, existirán conflictos de intereses. Personalmente, en estos casos donde el cargo ya ha acreditado su experiencia profesional previa no lo penalizaría con el período de enfriamiento. Otro caso distinto son los políticos de carrera, que no han tenido ningún otro oficio anteriormente a sus responsabilidades politicas, y que consiguen tras su cese pasar al sector privado como miembros de Consejos de Administración o altos directivos de empresas multinacionales (habitualmente que cotizan en el íbex-35) y ello debido a los contactos e influencias desarrolladas durante su mandato. En estos casos sería muy estricta con el cumplimento de los dos años de enfriamiento y mantener la compensación actual del $80 \%$ de su retribución anual para los miembros del gobierno, secretarios de Estado, el cargo de Fiscal Superior del Estado, los máximos responsables de los organismos reguladores y el Jefe y secretario general de la Casa de S.M. el Rey. En el resto de cargos, que no tienen compensación económica tras el cese, el criterio debería ser autorizar únicamente durante los dos años post-cargo aquellas solicitudes en las que no se apreciara en absoluto un conflicto de intereses. Por otro lado, existen

\footnotetext{
${ }^{7}$ El estudio realizado por la Fundación Hay Derecho en Marzo de 2017 sobre las puertas giratorias en la Administración General del Estado y el papel de la Oficina de Conflicto de Intereses muestra como entre noviembre 2006 y octubre de 2016 se emitieron un total de 377 autorizaciones a un total de 199 altos cargos públicos tres su cese, del total de 199 altos cargos que recibieron autorización por parte de la Oficina de Conflictos de Intereses para el ejercicio de una actividad privada en los dos años siguientes a su cese, 137 (el 69\%) solicitaron autorización para el desempeño de una única actividad. Es decir, los 62 altos cargos restantes fueron autorizados para el desarrollo de 2 o más actividades profesionales. En dicho periodo solo se denegaron 6 solicitudes.

8 Informe de evaluación de España. Quinta ronda de Evaluación. Prevención de la corrupción y promoción de la integridad en Gobiernos Centrales (altas funciones ejecutivas) y Fuerzas y Cuerpos de Seguridad. GRECO. 21 de junio de 2019. Pág. 27.
} 
altos cargos de la AGE que tienen la condición de funcionarios públicos y pueden regresar al servicio activo después de la situación de servicios especiales ${ }^{9}$.

\subsection{La captura reguladora y técnica}

Partiendo de la idea de que el Estado regulador tiene como objetivo incentivar la competencia y proteger los derechos de los ciudadanos, las agencias reguladoras tienen la misión de vigilar el mercado e intervenir cuando se precise para corregir sus fallos. Existe el riesgo que dichas agencias reguladoras sean capturadas por los intereses de mercado, bien por las relaciones entre las grandes empresas y los responsables de las agencias o porque existe corrupción (Vallejo, 2016: 21). En este sentido, según Guimaray (2016:131) existe una forma de captura legislativa correcta o legalmente permitida cuando el lobby realiza una acción de influencia legítima, aunque se podría distorsionar cuando busque regulaciones laxas, precios altos y sanciones mínimas, porque la captura distorsionaría las reglas de regulación a favor de una empresa o sector eliminando la eficiencia entre el servicio y sus costos. Y también existe el riesgo de que se capture al regulador de forma ilicita, es decir cuando las empresas quieren influir en la formulación de leyes, políticas y reglamentación del Estado, a cambio de pagos ilícitos y por tanto mediante conductas corruptas.

En la actualidad la mayor parte de la influencia sigue siendo oculta e informal y determinados grupos tienen un acceso privilegiado a los decisores públicos y los riesgos de la influencia indebida son altos a pesar de los intentos de gobiernos y lobistas de promover estándares de lobbies transparentes y éticos. De hecho 6 de cada 10 ciudadanos europeos consideran que su gobierno está afectado por intereses particulares (Mulcahy, 2015:6).

En España existe la idea muy arraigada de que el dinero compra la influencia en la política y que los negocios van de la mano de la corrupción. Y que las grandes corporaciones y grupos de interés influyen de manera indebida (aunque no ilegal) en la toma de decisiones políticas. En este sentido el barómetro publicado y realizado por la Oficina Antifrau de Catalunya en el año 2020 muestra que un 78,6\% considera que hay vínculos demasiado estrechos entre negocios y política y el 69,7 $\%$ considera que hay falta de transparencia en las decisiones públicas. ${ }^{10}$

\footnotetext{
9 Según Resolución de acceso a información pública del Ministerio de Política Territorial y Función Pública de 17 de septiembre de 2020, en el Registro Central de Personal de la Administración General del Estado constan como miembros del Gobierno o como altos cargos de la AGE y su sector público, 735 efectivos. Dentro de los cuales, 412 poseen al menos una relación de servicio abierta como funcionario de carrera de la misma administración o de las Universidades Públicas.

10 Oficina Antifrau de Catalunya. 2020. Baròmetre. La corrupció a Catalunya: Percepcions $i$ actituds ciutadanes.
} 
Es por ello que se hace necesario clarificar que el ejercicio del lobby y la captura regulatoria son fenómenos distintos, aunque se puede afirmar que el lobbismo puede ser el instrumento necesario y previo para que se produzca la captura.

\section{Las medidas de prevención}

Para que la actividad de los grupos de interés pueda tener un impacto positivo en el funcionamiento de las instituciones públicas, existen según Bernadi y Cerrillo (2017:3) tres parámetros para evitar influencias indebidas, irregularidades y casos de corrupción. Es necesario asegurar en primer lugar la transparencia de la actividad que llevan a cabo; la integridad tantos de los servidores públicos como de los mismos grupos de interés; y finalmente la igualdad en su acceso a las instituciones públicas.

\subsection{La transparencia}

Por lo que hemos visto, que la actividad de los lobbies sea pública y transparente es fundamental para evitar los riesgos de corrupción y ello se consigue principalmente a través de dos instrumentos: la regulación de su actividad a través del registro de grupos de interés con carácter obligatorio y la publicación de la agenda, no solo de los altos cargos sino también de los mandos a nivel de subdirección.

\subsubsection{La obligatoriedad del registro}

Actualmente a nivel del poder ejecutivo y legislativo estatal no existe una normativa que regule la actividad de los grupos de interés, a pesar de diversas iniciativas parlamentarias que han fracasado (Navarro; Andrés, 2016:9). Sí que existe el registro de grupos de interés de la Comisión Nacional de los Mercados y Competencia $(\mathrm{CNMC})^{11}$, así como los registros de grupos de interés de diversas Comunidades Autónomas como la de Catalunya ${ }^{12}$, la Comunidad Valenciana ${ }^{13}$, Castilla-La Mancha ${ }^{14}$, Asturias $^{15}$, Navarra ${ }^{16}$, Aragón $^{17}$ y Madrid ${ }^{18}$. También existen

\footnotetext{
${ }^{11}$ Mediante Resolución del Presidente de la CNMC se creó el 26 de febrero de 2016 el registro de grupos de interés con el objetivo de dar conocimiento público de la existencia y actividad de los grupos de interés en relación con la CNMC.

12 Mediante Decreto 171/2015, de 28 de julio se creó el Registro de grupos de interés de la Administración de la Generalitat de Catalunya y su sector público, modificándose a partir del Decreto Ley Decreto Ley 1/2017, de 14 de febrero, para transformarse en el registro de grupos de interés de todos los poderes públicos de Catalunya, incluida la Administración Local.

13 Ley 25/2018, de 10 de diciembre, reguladora de la actividad de los grupos de interés de la Comunidad Valenciana.

14 Ley 4/2016, de 15 de diciembre, de transparencia y buen gobierno de Castilla-La Mancha y Decreto 8/2018, de 20 de febrero, que crea y regula el Registro de grupos de interés de Castilla-La Mancha.
} 
registros de grupos de interés a nivel municipal como es el caso del Ayuntamiento de Madrid $^{19}$.

No obstante, la existencia de dichos registros de lobbies carece de relevancia si dicha inscripción no es obligatoria. Así, podemos encontrar registros como los autonómicos anteriormente citados que requieren una inscripción para poder tener un contacto con el alto cargo o representante de la Administración. Por otro lado, tanto el Registro de la CNMC, como el Registro de Transparencia del Parlamento y la Comisión Europea son actualmente de inscripción voluntaria. ${ }^{20}$

En mi opinión, el hecho de que el registro de los grupos de intereses sea voluntario hace perder eficacia a dicho instrumento como sistema de prevención de la corrupción o de las influencias indebidas. Nada impide a los miembros del Consejo de Administración o al personal directivo de la Comisión Nacional de los Mercados y Competencia reunirse y mantener contactos con empresas de l'IBEX-35 que no estén registradas.

Una solución si no se quiere reformar la obligatoriedad de la inscripción en dicho registro, pasaría por modificar el Reglamento de funcionamiento interno de la CNMC imponiendo la prohibición a su personal directivo y miembros de los órganos de gobierno, de contactar con los grupos de interés si estos no están registrados.

\footnotetext{
15 Ley del principado de Asturias 8/2018, de 14 de septiembre, de transparencia, buen gobierno y grupos de interés. Pendiente de desarrollo reglamentario.

16 Ley foral de Navarra 5/2018, de 17 de mayo, de transparencia, acceso a la información pública y buen gobierno. El art. 47 de la Ley prevé la creación de un registro Público de grupos de interés en el plazo de un año.

17 Ley 5/2017, de 1 de junio de integridad y éticas públicas de Aragón. Pendiente de regulación reglamentaria.

${ }^{18}$ Ley 10/2019, de Transparencia y Participación de la Comunidad de Madrid, que crea el Registro de Transparencia. Pendiente de regulación reglamentaria.

19 Ordenanza de Transparencia del Ayuntamiento de Madrid aprobada por el Pleno de 27 de julio de 2016.

20 En el caso del Registro de Transparencia del Parlamento y Comisión Europea desde el 16 de abril de 2018 se está llevando a cabo una ronda de negociaciones para impulsar dicha obligatoriedad.
} 


\subsubsection{La información pública de las agendas de los altos cargos públicos}

Sorprende que las leyes de transparencia aprobadas por las Comunidades Autónomas incluyan la publicación de las agendas de los altos cargos dentro de las obligaciones de publicidad activa, y no lo haga la ley estatal. Ello ha llevado a que el Consejo de Transparencia y Buen Gobierno, organismo público creado por la Ley 13/2019, de 9 de diciembre de Transparencia, Acceso a la Información y Buen Gobierno (LTAIBG), haya recibido numerosas reclamaciones en relación a solicitudes de acceso a la información, sobre las agendas de los miembros del Gobierno y altos cargos de la Administración General del Estado con especial referencia a las reuniones o visitas que mantenían. Fruto de dichas reclamaciones el Consejo de Transparencia y Buen Gobierno dictó la Recomendación 1/2017 sobre información de las Agendas de los responsables públicos. En ella el Consejo se pronunciaba en el sentido de que, si bien es cierto que los contenidos de las agendas de los altos cargos no están, en principio, afectados por el principio de publicidad activa del artículo 6 y siguientes de la LTAIBG que obliga a publicar de oficio determinada información de carácter institucional, organizativa y de planificación de interés jurídico, económico, presupuestario o estadístico, sí consideraba de interés la agenda de trabajo del responsable público y diferenciaba entre un primer nivel a los miembros del Gobierno y los secretarios de Estado o equivalente y en una segunda fase extender la recomendación de publicación a todos los responsables públicos de la AGE y del sector público institucional estatal, esto es, a los altos cargos así como los máximos responsables de las autoridades y entidades de ámbito estatal incluidas en el artículo 2 de la LTAIBG. El Consejo otorgaba un plazo de 6 meses des de la aprobación de la Recomendación para la publicación de las agendas del primer nivel y el plazo de un año para la segunda fase.

Actualmente como se puede comprobar en el Portal de Transparencia de la Administración General del Estado la única agenda que se publica es la del Presidente y miembros del gobierno, pero no la de los Secretarios de Estado y menos aún la del resto de altos cargos de la Administración.

El diagnóstico por tanto es que aún queda un camino por recorrer en cuanto a transparencia de las agendas de nuestros responsables políticos, y especialmente en el caso de la Administración General del Estado. Y viendo que a la práctica muchos grupos de interés y empresas optan por contactar con los niveles medios como los cargos de subdirección para eludir dicha publicidad, la obligatoriedad de publicación de la agenda debería hacerse extensiva a dichos niveles de la Administración. 


\subsubsection{La huella legislativa}

En mi opinión, deberia ser preceptiva la huella normativa (legislative footprint) en toda actividad regulatoria. De esta manera se podría detallar en un documento todo el proceso de elaboración de la norma, así como las personas físicas o juridicas que han contactado con los altos cargos responsables de dicha regulación, con el fin de poder comprobar que no ha habido una influencia $o$ captura indebida.

En este sentido Ponce (2019:125), en un análisis empírico innovador, analizó las reuniones de los responsables públicos del poder ejecutivo catalán con lobbies entre el 2016 y 2017 que supuso 561 encuentros con lobbies al mes (18 al día), en relación con proyectos de ley y reglamentos. El estudio concluye que el control es positivo, ya que permite conectar distintos elementos relevantes en la toma de decisiones en contextos de informalidad y lleva a una mejora de la gestión administrativa reguladora. Así mismo, encomienda a una futura regulación, pues España es de las pocas democracias avanzadas que no dispone de huella normativa.

\subsection{La integridad}

Existen evidencias internacionales de que la corrupción se combate mejor con el fomento de un buen gobierno imparcial, eficiente y responsable que castigando a los corruptos ${ }^{21}$.

Desde esta perspectiva y con el objetivo de restablecer la confianza, no sólo con los gobierno, sino también con todas las instituciones públicas, los reguladores, los bancos y las empresas, la OCDE ${ }^{22}$ ha puesto a disposición de los gobernantes una guía para el diseño de una estrategia de integridad pública basada en tres pilares: disponer de un sistema para reducir las oportunidades de comportamiento corrupto; cambiar la cultura para hacer que la corrupción sea socialmente inaceptable; y haciendo que la gente sea responsable de sus acciones.

\footnotetext{
${ }^{21}$ Por encargo de la Secretaria de Transparència i Govern Obert de la Generalitat de Catalunya, el Institut Català d'Avaluació de Polítiques Públiques realizó un estudio en septiembre de 2019 Estratègies Marc contra el Frau i la Corrupció. Revisió de la Literatura Especialitzada. Dicho estudio realiza una revisión de las estrategias llevadas a cabo por diferentes países que han conseguido con éxito reducir los índices de corrupción en sus países. Medidas como simplificar los procesos burocráticos y reducir las regulaciones, así como la discrecionalidad de los políticos, las políticas basadas en el control, como las auditorias, el uso de las tecnologias de la información para potenciar el e-government o la protección de los medios de comunicación, la separación de carreras entre funcionarios y políticos, revisar los sueldos públicos, potenciar las motivaciones intrínsecas del trabajadores y seleccionarlos en base al mérito, el acceso a la información, o la protección de los denunciantes, forman parte de una buena estrategia para reducir el fraude y la corrupción.

22 Recomendación de la OCDE sobre Integridad Pública (2017) que actualiza la recomendación sobre la mejora de la Conducta Ética en el Servicio Público (1998).
} 
En la misma línea Transparencia Internacional (TI) ha desarrollado el concepto Sistema Nacional de Integridad (SNI) como parte integrante de su enfoque holístico de lucha contra la corrupción. La conclusión del análisis efectuado por dicho organismo (Villoria, 2012:337) es que la democracia española está controlada por los grandes partidos políticos, lo que reduce y desincentiva el involucramiento de la ciudadanía en el espacio público. En el caso de las grandes empresas, su negocio depende en gran parte de su relación con el sector público, lo que provoca que se busquen relaciones cordiales con los partidos que gobiernan. Asimismo, destacan los bancos como organizaciones que influyen en las finanzas de los partidos políticos, convirtiéndose esta conexión en una vía para la captura de políticas. La integridad queda con frecuencia en el apartado de las declaraciones simbólicas y su implantación choca frecuentemente con los intereses de los grupos dominantes.

Actualmente, en el ámbito de las Administraciones Públicas, el control de los riesgos de corrupción se confía a las normas de carácter general, como las de conflictos de interés e incompatibilidades, las leyes de transparencia, acceso a la información y buen gobierno, y los códigos éticos generales. Pero hay que implementar la misma metodología y sistemática que en el Compliance Penal aplicado a las personas juridicas, y de ahí que sea imprescindibles que las Administraciones Púbicas dispongan también de un mapa o análisis de riesgos, un procedimiento o canal de denuncias apropiado y un organismo de control interno y externo, y todo ello configurando el llamado sistema o marco de integridad institucional. Dicho sistema de la integridad institucional deberá actuar sobre tres ejes clave de la organización: fomentando una cultura ética interna, una gestión pública profesional y previniendo la corrupción con una eficaz prevención y gestión de los conflictos de intereses.

Un caso práctico de cómo una Administración puede construir un sistema de Integridad Institucional o Public Compliance lo podemos encontrar en el caso del gobierno autonómico catalán. Es un ejemplo paradigmático por la forma de elaboración a través de un proceso abierto y participativo, que lo dota de legitimidad.

Mediante Acuerdo del Gobierno de la Generalitat de Catalunya del mes de enero de 2020, se aprobó la Estrategia de lucha contra la corrupción y de fortalecimiento de la integridad con el objetivo de implementar 25 actuaciones en el plazo de dos años. Dichas actuaciones se centran principalmente en ámbitos como la contratación pública, la fiscalidad, las subvenciones, la función y dirección públicas, las incompatibilidades, los conflictos de interés y grupos de interés, la protección de alertadores y la anonimización de buzones éticas, y los marcos de integridad, con un acento especial en todos aquellos aspectos relacionados con la imparcialidad y con el control de la influencia ilegitima en las tomas de decisiones 
públicas. En relación a los grupos de interés, la Estrategia establece que se deberá determinar el contenido mínimo de las agendas de los altos cargos y directivos públicos que se debe hacer pública, para garantizar una homogeneidad y accesibilidad y comprensión por parte de la ciudadanía. Así mismo, se deberán publicar las propuestas normativas presentadas por los grupos de interés.

\subsection{La igualdad de acceso}

Finalmente, un tercer elemento para que la actividad legítima de los grupos de interés tenga un efecto positivo seria garantizar la igualdad de acceso de todos ellos. En el seno de las instituciones europeas es muy relevante las diferencias entre ONG i grandes corporaciones multinacionales, y que Dialer y Richter (2019:4) caracterizan como "David contra Goliat". Grandes lobbies del automóvil, energía, farmacia, tabaco, alimentos, agroindustria acceden a la influencia política especialmente en la etapa prelegislativa. No todos los intereses están representados en igualdad de condiciones.

Según Transparencia Internacional ${ }^{23}$ España está dotada con mecanismos débiles de consulta y participación en la toma de decisiones y no se garantiza suficientemente la pluralidad e inclusión de todos los intereses por igual. Cabe recordar, que la participación en los asuntos públicos por parte de la ciudadanía es un derecho constitucionalmente reconocido (art. 23 CE) y que la participación pública en la elaboración de las normas se recoge en el art. 133 de la Ley 39/2015. de 1 de octubre del Procedimiento Administrativo Común de las Administraciones Públicas.

Pero más allá del ámbito de elaboración de las normas y del ámbito regulatorio, donde es necesario garantizar la igualdad de acceso de los grupos de interés, por el mayor riesgo de corrupción, es en el ámbito de la contratación pública.

La contratación pública es una de las actividades gubernamentales más vulnerables a la corrupción por el volumen de las transacciones y los intereses financieros en juego. Los riesgos de corrupción se ven exacerbados por la complejidad del proceso y la estrecha interacción entre los funcionarios públicos y las empresas y la multitud de partes interesadas. El Informe de la OCDE sobre cohecho internacional $(2014)^{24}$ proporciona evidencias de que la contratación pública es vulnerable a la corrupción. Más de la mitad de los sobornos son casos ocurridos para obtener una contratación pública en sectores estrechamente

\footnotetext{
23 Estudio "El Lobby en Europa. Influencia encubierta, acceso privilegiado". Transparency International (2015).

24 OECD. 2014. OECD Foreign Bribery Report: An Analysis of the Crime of Bribery of Foreign Public Officials, OECD Publishing, Paris.
} 
asociados con la construcción, el transporte, el almacenamiento y sectores de la información y la comunicación.

Por otro lado, según el Observatorio de Contratación Pública ${ }^{25}$ ésta representa el $20 \%$ del PIB de España y la falta de competencia en las licitaciones públicas impone sobrecostes de aproximadamente 40.000 millones de euros anuales ${ }^{26}$.

No obstante, el fenómeno de la corrupción en la contratación pública debe tener una aproximación más amplia que la establecida en las definiciones especialmente recogidas en la normativa europea ${ }^{27}$ que requieren para apreciar corrupción que exista una compensación o intercambio ilegítimo, que podría excluir practicas tradicionalmente corruptas en las que no existe un intercambio, como son el nepotismo o el favoritismo. Por tanto, se debería incluir en el concepto de corrupción en la contratación pública aquellos actos conscientes contra el interés público que generen o pretendan generar una ventaja indebida (Miranzo, 2019:3).

En este sentido existe el riesgo, especialmente en la fase previa de la contratación, que a través de influencias indebidas la Administración inicie una licitación pública sin que sea necesaria para los ciudadanos ni exista una justificación de la inversión pública en dicho contrato desde un punto de vista social ni económico. Otro momento crucial es el de la selección de las ofertas y la adjudicación del contrato, siendo la principal forma de corrupción cuando el órgano adjudicador no es imparcial por la existencia de comisiones, sobornos, conflictos de intereses $u$ otro tipo de influencias (Ballesteros, 2017:2).

Y a pesar de que popularmente se pueda asociar la influencia de determinados grupos de interés la adjudicación de grandes contratos millonarios, normalmente de inversión de obra pública, considero que hoy en día la Ley 9/2017, de 8 de noviembre, de contratos de sector público (LCSP), tras la transposición de diversas directivas europeas ${ }^{28}$, es un buen instrumento contra las prácticas corruptas. La propia ley establece que los órganos de contratación deberán tomar las medidas

25 Véase www.obcp.es

26 Ver la Guía contra el fraude en la licitación pública publicada por la CNMC: Comisión Nacional de los Mercados y la Competencia. 2020. Guía sobre contratación pública y competencia.

27 Art. 57.1 de la Directiva 2014/24/UE del Parlamento Europeo y del Consejo de 26 de febrero de 2014

sobre contratación pública, tal como se define corrupción en el artículo 3 del Convenio relativo a la lucha contra los actos de corrupción en los que estén implicados funcionarios de las Comunidades Europeas o de los Estados miembros de la Unión Europea (2) y en el artículo 2, apartado 1, de la Decisión marco 2003/568/JAl del Consejo (3), o corrupción tal como se defina en la legislación nacional del poder adjudicador o del operador económico.

28 Directivas del Parlamento Europeo y del Consejo 2014/23/UE y 2014/24/UE, de 26 de febrero de 2014. 
adecuadas para luchar contra el fraude, el favoritismo y la corrupción, y prevenir, detectar y solucionar de modo efectivo los conflictos de intereses que puedan surgir en los procedimientos de licitación con el fin de evitar cualquier distorsión de la competencia y garantizar la transparencia en el procedimiento y la igualdad de trato a todos los candidatos y licitadores (art. 64 LCSP/2017), al tiempo que se prohibe la contratación con quienes hayan sido condenados mediante sentencia firme por delitos de corrupción (art. 71.1 a) LCSP).

En mi opinión, el riesgo de ser imparcial en la adjudicación por influencias indebidas es mayor en la contratación menor al ser más laxos los requisitos de adjudicación, debido a que la ley permite la adjudicación directa en contratos de menos de 15.000 euros, a pesar que se recomiende la valoración de tres ofertas distintas $^{29}$. Prácticas como pactar los importes del contrato para no superar el importe máximo de la contratación menor y eludir la concurrencia; que las tres ofertas presentadas pertenezcan a empresas del mismo grupo empresarial o que los presupuestos los aporte un mismo licitador, son hechos que aún perduran en nuestras Administraciones, de ahi la importancia como hemos visto en el apartado interior, de la necesidad de reforzar la integridad de nuestros responsables políticos.

Un mecanismo idóneo para garantizar la igualdad de acceso a la contratación pública son las consultas preliminares de mercado ${ }^{30}$ que están sujetas a los principios generales de la contratación pública como son la publicidad, transparencia, no discriminación e igualdad de trato. Actualmente la normativa vigente (art. 115 LCSP) permite una configuración discrecional de la tramitación de estas consultas por ello se hace necesario un desarrollo reglamentario de dicho procedimiento. Generalizar dichas consultas permite a la Administración informar a los operadores económicos sobre sus planes y requisitos que se exigirán para concurrir a un potencial procedimiento de adjudicación.

\footnotetext{
29 Resolución de 6 de marzo de 2019, de la Oficina Independiente de Regulación y Supervisión de la Contratación, por la que se publica la Instrucción 1/2019, de 28 de febrero, sobre contratos menores, regulados en la Ley $9 / 2017$, de 8 de noviembre.

30 Las consultas preliminares de mercado fueron introducidas por el artículo 40 de la Directiva 2014/24/UE como un instrumento para preparar las licitaciones públicas e informar a los operadores económicos sobre los planes y requisitos de las licitaciones del sector público.
} 


\section{Conclusiones}

Hay que socializar la cultura del lobbismo, entendida como un elemento de garantía de representatividad de los sistemas democráticos, y también como un mecanismo facilitador de conocimiento técnico a los gobernantes y decisores públicos.

No obstante, debemos garantizar un funcionamiento transparente y ético de los lobbies para evitar riesgos de corrupción como las puertas giratorias y la captura reguladora, ya que los conflictos de intereses son el componente necesario para que exista corrupción. La tipificación del delito de tráfico de influencias que debía delimitar la línea roja entre la actividad legitima de los grupos de interés y la delictiva se ha mostrado ineficiente en su cometido, por ello se hace necesaria su revisión y orientación contra las grandes redes de tráfico.

Por último, es preciso trabajar en la prevención de los riesgos de corrupción de los lobbies con medidas como la transparencia a través del registro obligatorio de los grupos de interés y la publicación de la agenda de los altos cargos y cargos medios con responsabilidad directivas; la elaboración de sistemas de integridad institucional y la igualdad de acceso de todos los intereses, no solo en el ámbito regulatorio, sino especialmente en el ámbito de la contratación pública por ser uno de los ámbitos más vulnerables a la corrupción.

Hemos puesto los cimientos de las políticas de transparencia y se están consolidando, pero debemos continuar construyendo y reforzando cada uno de sus elementos, y la regulación de los lobbies es una pieza fundamental. 


\section{Bibliografía}

Ballesteros Fernández, G. 2017. "Riesgos de corrupción en contratos públicos. Como prevenir malas prácticas". Revista Internacional Transparencia e Integridad, 5, 1-6.

Bernadi Gil, X; Cerrillo Martínez, A; 2017. "Transparència, integritat i grups d'interès. Deu lliçons apreses de l'aplicació de La Llei 19/2014, de 29 de desembre." Revista Catalana de Dret Públic, 55, 1-22.

Bobbio, N; Matteucci, N; Pasquino, G. 1997. Diccionario de Politica, tomo I. México, Siglo XXI, décima edición.

Cugat Mauri, M. 1997. La desviación del interés general y el tráfico de influencias. Rubi: Cedecs.

Cugat Mauri, M. 2014. "El tráfico de influencias. Un tipo prescindible". Revista Electrónica de Ciencia Penal y Criminológica. 16-07, 1-23.

Dialer, D., Richter, 2019 "Lobbying in Europe: Professionals, Politicians, and Institutions Under General Suspicion?" in Dialer, D., Richter, M. (ed.) Lobbying in the European Union: strategies, dynamics and trends. Cham, Switzerland: Springer, 2019.

R M. Lobbying in the European Union: strategies, dynamics and trends. Cham, Switzerland: Springer, 2019.

Garcia Guitian, E. 2016. "Representación y Gobernabilidad: Una reflexión sobre el rol de los ciudadanos organizados en las democracias", en Molins, J; Muñoz; L; Medina, I. (coord.), Los grupos de interés en España. Madrid: Tecnos, pp. 63-83.

Guimaray Mori, Erick. 2016. "Sobre la captura del regulador y el injusto penal de colusión". Themis-Revista de Derecho, 68, 129-137.

Malem Seña, J.F. 2016. "La corrupción política". Anuario del Departamento de Derecho de la Universidad Iberoamericana. 31, 579-595.

Martinez Galindo, G. 2005, "El delito de tráfico de influencias en la Administración Local", La Ley Penal, Núm. 22, pp. 36-50.

Martins Lampreia, J. 2006. Lobby. Ética, Técnica y Aplicación. Madrid, Textos Editores.

Michels, R. 2001. Los partidos políticos I y II. Un estudio sociológico de las tendencias oligárquicas de la democracia moderna. Buenos Aires: Amorrortu. 
Miranzo Díaz, J. 2019. "El necesario cambio de paradigma en la aproximación a la corrupción en la contratación pública europea: propuestas para su sistematización", Revista General de Derecho Administrativo, 51.

Mulcahy, S. 2015. "El lobby en Europa. Influencia encubierta, acceso privilegiado". Transparency International. pp. 6-7.

Muñoz Lorente, J. 2013. "Los delitos de tráfico de influencias (Situación actual y propuesta de reforma en la lucha contra la corrupción". Eunomía. Revista en Cultura de la Legalidad. 4, 73-101.

Navarro, J; Andrés, C. 2016. "Lobbyng". Eunomía. Revista en Cultura de la Legalidad. 10, 191-201.

Ponce Solé, J. 2019. Mejora de la regulación, lobbies y huella normativa. Valencia: Tirant lo Blanch. pp. 125-130.

Revuelta, A; Villoria, M. 2016. "La regulación de los grupos de interés como instrumento de prevención de la corrupción." en Villoria Mendieta, M; Gimeno Feliu, J.M.; Tejedor Bielsa, J (Dir). La corrupción en España. Ámbitos, causas y remedios jurídicos. Barcelona: Atelier.

Vallejo Almeida, G. 2016. "La captura regulatoria y su relación con las fallas del mercado" en J. A. Cubides Cárdenas, J. E. Pinilla Malagón, J. Torres Ávila, Vallejo Almeida, G. Derecho público en el siglo XXI: regulación del mercado, contratación pública y derechos humanos. Bogotá: Universidad Católica de Colombia.

Villoria Mendieta, M. 2012. El marco institucional de integridad en España: Situación actual y recomendaciones. Valencia: Tirant lo Blanch.

Xifra, J. 1998. Lobbying. Cómo influir eficazmente en las decisiones de las Instituciones Públicas. Barcelona: Gestión 2000. pp. 13-33.

Xifra, J. 2009. Els lobbies. Barcelona: UOC. 